\title{
Non-penetrance in tuberous sclerosis
}

\author{
David W Webb, John P Osborne
}

\begin{abstract}
Non-penetrance has not been reported in tuberous sclerosis when modern non-invasive investigations have been performed. We report a four generation family in which there was a subject with minimal expression and another with non-penetrance between a great grandfather and his great grandson. This situation highlights the need for full investigation of children of tuberous sclerosis patients before counselling a low recurrence risk for the disease.
\end{abstract}

The skipped generation is a well recognised feature of autosomal dominant conditions and should imply non-penetrance. It can only be considered to have occurred when the non-penetrant subject has both an affected parent and an affected child: in addition the non-penetrant subject must have been rigorously investigated to exclude minimal features of the phenotype.

Using modern standards of investigation skipped generations have not been reported in tuberous sclerosis. However, minimal expression of the phenotype is a well recognised feature of the disease. We report a family who have been thoroughly investigated and have a subject with minimal expression and another with non-penetrance between a great grandfather and his great grandson.

\section{Case report}

A 40 year old man had a father and two sibs with tuberous sclerosis. He was examined for a genetic linkage study clinically and with ultraviolet light and direct fundoscopy and, in addition, had a cranial CT scan, renal ultrasound, and $x$ ray skeletal survey. All investigations proved normal. His three children were also examined clinically and with Woods light and direct fundoscopy and because of negative findings

Bath Unit for Research into Paediatrics, Royal United Hospital, Combe Park, Bath BAl 3NG.

D W Webb, J P Osborne

Correspondence to Dr Osborne.

Received for publication 23 October 1990.

Revised version accepted for publication 10 December 1990. were counselled as having a negligible recurrence risk for the disease.

Two years later his daughter's first child suffered his first fit lasting 35 minutes, eight days after a measles, mumps, and rubella immunisation at 13 months of age. On examination the boy had several hypomelanic macules typical of tuberous sclerosis. $\mathrm{He}$ also had a retinal phakoma and on cranial CT scan there were multiple calcified periventricular nodules. He has suffered no fits since but his development, which was previously normal, is now retarded. His great grandfather has facial angiofibromas, hypomelanic macules, and ungual fibromas. The child's grandfather was re-examined clinically, with ultraviolet light, and by direct and indirect fundoscopy. He was found to have a single fleshy ungual fibroma (fig 1) on the little toe of his left foot. This had not been there when he was first seen or when he had last cut his toe nails. No other signs were found. A cardiac ultrasound showed two probable rhabdomyomata in the right ventricular wall and right ventricular outflow tract (fig 2). Cranial magnetic resonance imaging was normal.

The child's mother was also re-examined clinically and with ultraviolet light, direct and indirect fundoscopy, cranial CT scan, renal ultrasound, echocardio-

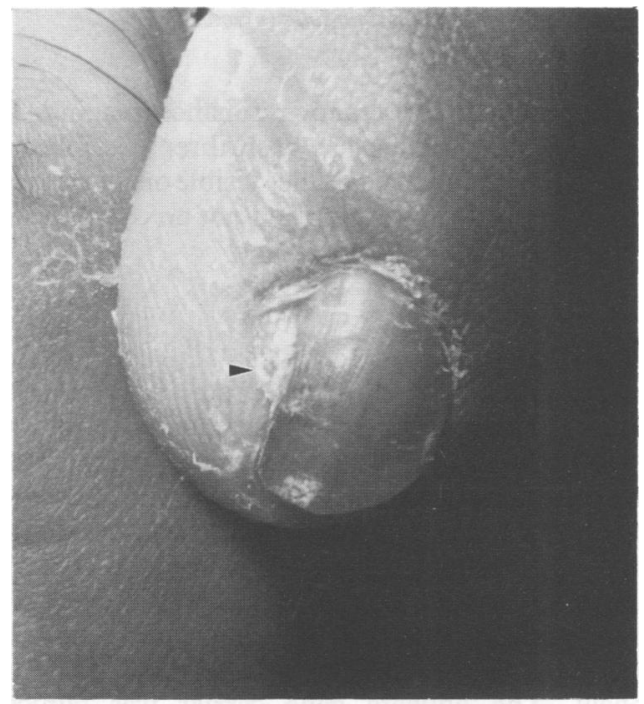

Figure 1 A fleshy ungual fibroma (arrowed). 

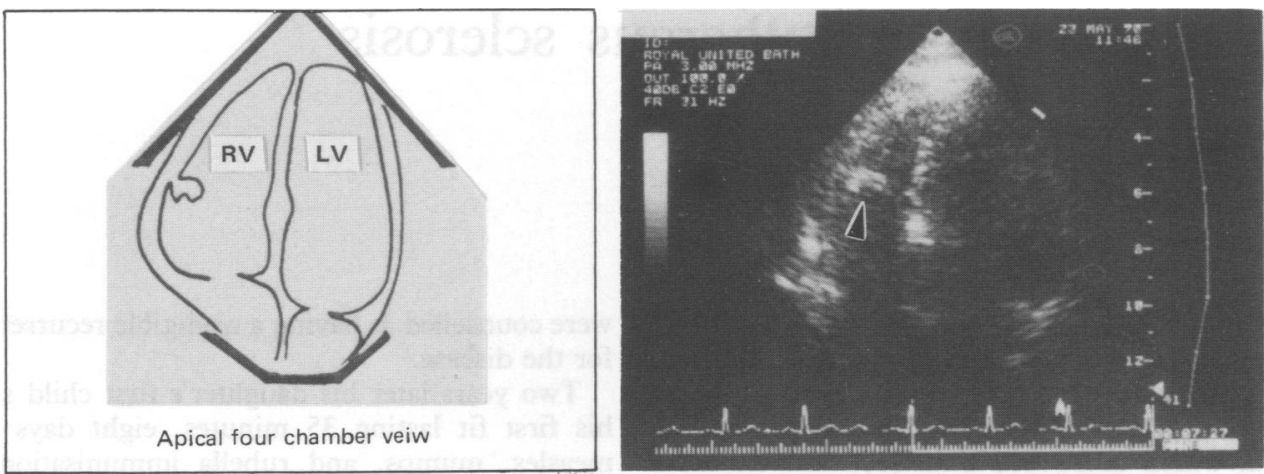

Figure 2 A probable cardiac rhabdomyoma protruding from the right ventricular wall (arrowed).

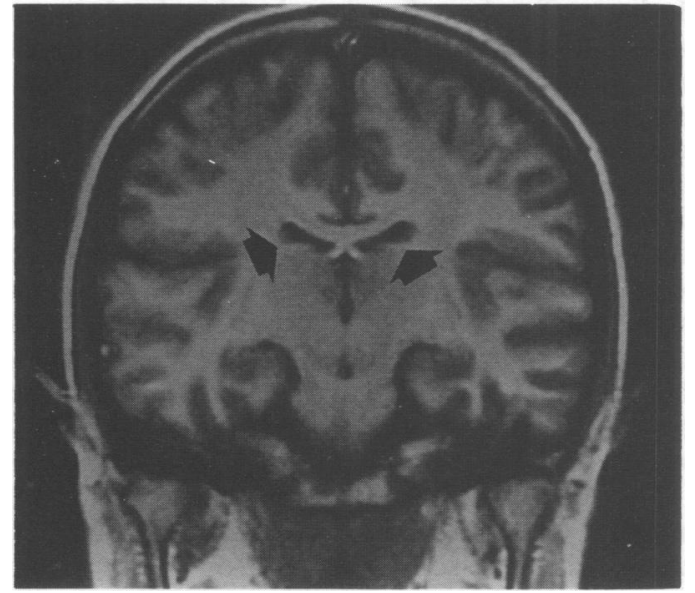

Figure 3 A cerebral magnetic resonance image with possible non-calcified subependymal nodules (arrows).

graphy, and cranial magnetic resonance imaging. The only significant finding has been three possible noncalcified subependymal nodules visible on TI weighted magnetic resonance imaging and not on computerised tomography (fig 3).

\section{Discussion}

Non-penetrance is clearly a rare occurrence in tuberous sclerosis. There is one previously reported case of affected first cousins whose parents were probable obligate carriers and who were found to be normal on clinical examination and who had normal cranial CT scans. ${ }^{1}$ Renal ultrasound, echocardiography, and cranial magnetic resonance imaging were not performed. Rushton and Shaywitz ${ }^{2}$ reported a three generation family with an affected uncle and nephew. The obligate gene carrier was clinically normal but not investigated. Because of the protean manifestations of this disease, true non-penetrance can only now be considered to have occurred when modern techniques have been used to exclude the diagnosis in patients at risk. Two other previous reports are not adequate for this reason. ${ }^{34}$

Our case of minimal expression, the grandfather, was associated with the late appearance of an ungual fibroma and led to an inaccurate estimate of the risk of recurrence. Before being counselled this man was rigorously investigated in a manner felt to be appropriate at the time. It has recently been suggested that echocardiography may be a useful screening procedure $^{56}$ and this would have been helpful if it had been performed at an earlier date. The finding of multiple cardiac echodensities in a patient with a $50 \%$ risk for tuberous sclerosis would be sufficient to suggest, but not prove, the diagnosis. Echocardiography is likely to be most helpful in childhood as the lesions are more easily and more frequently seen than in adults. Sonographic-pathological correlations have not been established for the echodense lesions described in adults with the disease and for this reason we remain cautious about the interpretation of such lesions.

This man's daughter is as close as we have seen to representing true non-penetrance for this disease. She may in time develop cutaneous features of the disease, too late to be of help for her own genetic counselling. While calcified subependymal nodules are a primary diagnostic feature, the finding of uncalcified nodules which are apparent only on cranial magnetic resonance imaging and not on cranial CT scanning is not diagnostic. They may represent heterotopic grey matter and the scans have been thought by more than one neuroradiologist to be normal.

This family has been previously reported as a three generation family with no history of fits or mental retardation ${ }^{7}$ (the great grandfather is III.1). They highlight the problem of how to investigate children of tuberous sclerosis patients before counselling a 
negligible recurrence risk for the disease in future generations. Where a family member has a $50 \%$ prior risk for the disease rigorous investigation would seem reasonable, particularly as non-penetrance is so rare. Cranial CT scans should be performed. We have previously argued that renal ultrasound should not be included as part of a routine protocol to screen parents of an apparent sporadic case. ${ }^{8}$ It may be helpful if done early in life as isolated angiomyolipomata have not been reported in childhood in the absence of tuberous sclerosis. Single cysts which can cause problems of interpretation in adults are rare in childhood. Multiple renal cysts are more likely to represent tuberous sclerosis.

The situation of a second affected child born to clinically normal parents is a different problem and has been reported several times in tuberous sclerosis. ${ }^{-11}$ This might occur because of variable disease expression or true non-penetrance, but also because of non-paternity or germinal mosaicism. Despite all investigations it will therefore still be necessary to counsel a small recurrence risk to the parents of a sporadically affected child.

D W Webb is supported by a grant from the Tuberous Sclerosis Association of Great Britain and the Bath Unit for Research into Paediatrics. We thank Dr Bob Tan for bringing the family to our attention.
We would like to thank Mrs Alex Morefield for her help with the photographic material and Mrs Helen Hansen for secretarial support. We also thank Cow \& Gate Ltd, Glaxo Laboratories Ltd, and Avon Rubber plc for financial support.

1 Baraitser M, Patton MA. Reduced penetrance in tuberous sclerosis. F Med Genet 1985;22:29-31.

2 Rushton AL, Shaywitz BA. Tuberous sclerosis: possible modification of phenotypic expression by an unlinked dominant gene. 7 Med Genet 1979;16:32-5.

3 Gunther $M$, Penrose LS. The genetics of epiloia. $\mathcal{f}$ Genet 1935;31:314-428.

4 Vass J. Klinik und Erbgang der tuberosen sklerose. Arch Psychiatr

Nerv 1940;111:547-614

5 Al-Gazali LI, Arthur RJ, Lamb JT, et al. Diagnostic and counselling difficulties using a fully comprehensive screening protocol for families at risk for tuberous sclerosis. 7 Med Genet protocol for families

6 Smith HC, Watson GH, Patel RG, et al. Cardiac rhabdomyomata in tuberous sclerosis: their course and diagnostic value. Arch Dis Child 1989;64:196-200.

7 Fryer AE, Osborne JP, Tan R, et al. Tuberous sclerosis: a large family with no history of seizures or mental retardation. $\mathcal{f} M e d$ Genet 1987;24:547-8.

8 Fryer AE, Chalmers AH, Osborne JP. The value of investigation for genetic counselling in tuberous sclerosis. $f$ Med Genet 1990;27:217-23.

9 Wilson J, Carter C. Genetics of tuberous sclerosis. Lancet 1978;i:340.

10 Lowry RB, Dunn HG, Paris RP. Inheritance of tuberous sclerosis. Lancet 1979; i:216.

11 Sampson JR, Scahill SJ, Stephenson JB, et al. Genetic aspects of tuberous sclerosis in the west of Scotland. $f$ Med Genet 1989;26:28-31. 